\title{
EFICÁCIA DO HERBICIDA CHLORIMURON-ETHYL NO CONTROLE DE Melampodium perfoliatum NA CULTURA DA SOJA
}

\author{
Júlio P. Laca-Buendia ${ }^{1}$ e Paulo F. Maricondi ${ }^{2}$
}

${ }^{1}$ EPAMIG, Av. Amazonas, 115 - Sala 619 - Belo Horizonte, MG 30180 - 902

? Du Pont do Brasil S.A. - Caixa Postal 263 - Barueri, SP 06454 - 080

\section{RESUMO}

Uma nova e importante planta daninha está ocorrendo em lavouras de soja nos cerrados do Estado de Minas Gerais. O objetivo do ensaio de campo a atividade biológica e a tolerância da cultura de soja cv. 'IAC-8' ao herbicida chlorimuron-ethyl isoladamente e em mistura, quando aplicados em pós-emergência, para o controle da estrelinha (Melampodium perfoliatum), em área de Cerrado, em Latossolo Vermelho-Escuro. Os tratamentos foram: chlorimuron-ethyl (12,5 e $15 \mathrm{~g} / \mathrm{ha})+$ óleo mineral (0,05\% $\mathrm{v} / \mathrm{v})$, chlorimuron-ethyl + lactofen a $12,5+120 \mathrm{~g} / \mathrm{ha}$, chlorimuron-ethyl + fomesafen $(12,5+150 \mathrm{~g} / \mathrm{ha})+$ óleo mineral $(0,1 \% \mathrm{v} / \mathrm{v})$, chlorimuron-ethyl + imazethapyr a $12,5+30 \mathrm{~g} /$ ha e testemunha capinada e sem capina. O chlorimuron-ethyl ( 12,5 e $15 \mathrm{~g} / \mathrm{ha})+$ óleo mineral $(0,05 \% \mathrm{v} / \mathrm{v})$, apresentou eficiente controle da estrelinha, com 95\% e 97\% de controle. Quando o chlorimuron-ethyl foi misturado com lactofen, fomesafen e imazethapyr, mostrou um eficiente índice de controle, entre 96 e $99 \%$, até 132 dias após a aplicação. Chlorimuron-ethyl isolado e em mistura com lactofen, fomesafen e imazethapyr, nas doses testadas, mostrou-se altamente seletivo para a cultura da soja.

Palavras-chave: mistura de herbicidas, plantas daninhas, Glycine max.

\section{ABSTRACT \\ Efficacy of chlorimuron-ethyl in the control of Melampodium perfoliatum in soybean}

A new and important weed, Melampodium perfoliatum, has been growing in soybean plantations in the "Cerrados" of Minas Gerais, Brazil. The objective of this study was evaluate the biological activity and soybean tolerance to chorimuronethyl alone or tank mixed with other postemergence herbicides. Treatments were: chlorimuron-ethyl $(12.5 \mathrm{and} 15 \mathrm{~g} / \mathrm{ha})+$ mineral oil $(0.05 \% \mathrm{v} / \mathrm{v})$, chlorimuron-ethyl + lactofen at $12.5+120 \mathrm{~g} / \mathrm{ha}$, chlorimuon-ethyl + fomesafen $(12.5+150 \mathrm{~g} / \mathrm{ha})+\mathrm{mineral} \mathrm{oil}(0.1 \%$ $\mathrm{v} / \mathrm{v}$ ) chlorimuron-ethyl + imazethapyr at $12.5+30 \mathrm{~g} / \mathrm{ha}$ and a weedy and a weeded control. Results indicate that chlorimuronethyl (12.5 and $15 \mathrm{~g} / \mathrm{ha})+$ mineral oil has controlled efficiently (95 and 97\%) M. perfoliatum. When chlorimuron-ethyl was mixed with lactofen, and imazethapyr control increased to $96-99 \%$ up 132 days after application. Chlrimuron-ethyl alone or tank mixed with lactofen, fomesafen and imazethapyr has shown to be highly selective to soybean.

Keywords: herbicide tank mix, weeds, Glycine max.

\section{INTRODUÇÃO}

Com a recuperação dos solos de Cerrado em Minas Gerais, a cultura da soja tem alcançado expressivo progres- so, verificando-se que a ocorrência das plantas daninhas vem se tornando um problema sério, causando consideráveis danos à cultura e consequentemente na produtividade, além da depreciação na qualidade das sementes e dificultando a colheita mecânica. 
A planta daninha estrelinha ou botão-de-cachorro, é uma planta nativa do México e muito comum na América Central. Foi introduzida recentemente no Brasil, sendo constatada inicialmente na região de São Gotardo em Minas Gerais. Está se alastrando pelo Alto Paranaíba e Triângulo Mineiro, sendo encontrada em diversas localidades dos Estados de Minas Gerais e de Goiás. É uma planta daninha extremamente agressiva, competindo fortemente com culturas de ciclo anual, bem como dificultando a colheita mecânica (Kissmann, 1994).

O objetivo do ensaio de campo foi avaliar a atividade biológica e tolerância da cultura de soja ao herbicida chlorimuron-ethyl aplicado isolado e em mistura, em pósemergência, para o controle da estrelinha (Melampodium perfoliatum), em área de Cerrado.

\section{MATERIAL E MÉTODOS}

O ensaio foi instalado na Fazenda Santa Clara, no PADP-Lote 23/24, localizada no município de São GotardoMG, no ano agrícola 1993/94, em solo de Cerrado (Latossolo Vermelho-Escuro), com pH(água)=5,5 e 3,1\% de matéria orgânica.

A cultivar utilizada foi a 'IAC-8', semeada em 13/11/ 93, no espaçamento de 0,45 m entre linhas, deixando-se cair 17 sementes por metro linear, profundidade de 3 a $5 \mathrm{~cm}$, com semeadora de tração mecânica de quatro linhas. A adubação de plantio usada foi de $300 \mathrm{~kg}$ /ha da fórmula 2-20-20 de NPK.

Para controle das gramíneas aplicou-se trifluralin, a $960 \mathrm{~g} / \mathrm{ha}$, aplicado em pré-plantio incorporado em 12/11/93. Os tratamentos utilizados, todos em pós-emergência, estão discriminados na Tabela 1 .

Tabela 1. Produtos utilizados no ensaio. São Gotardo-MG, 1993.

\begin{tabular}{lllcc}
\hline \multicolumn{2}{c}{ Herbicidas } & & \multicolumn{2}{c}{ Dose } \\
\cline { 1 - 2 } \cline { 5 - 5 } Nome Comum & $\begin{array}{l}\text { Nome } \\
\text { Comercial }\end{array}$ & & (g/ha) & (/ha) \\
\hline Chlorimuron-ethyl $\left(^{*}\right)$ & Classic $\left(^{*}\right)$ & & 12,5 & $50 \mathrm{~g}$ \\
Chlorimuron-ethyl $\left(^{*}\right)$ & Classic $\left(^{*}\right)$ & & 15,0 & $60 \mathrm{~g}$ \\
Chlorimuron-ethyl + lactofen & Classic+ Cobra & $12,5+120$ & $50 \mathrm{~g}+0,51$ \\
Chlorimuron-ethyl + fomesafen $\left(^{*}\right)$ & Classic + Flex $\left(^{*}\right)$ & $12,5+150$ & $50 \mathrm{~g}+0,61$ \\
Chlorimuron-ethyl + imazethapyr & Classic + Pivot & $12,5+30$ & $50 \mathrm{~g}+0,31$ \\
Testemunha sem capina & - & - & - \\
\hline
\end{tabular}

(*) Utilizado óleo mineral (Assist) a 0,05\% v/v.

O ensaio foi instalado em blocos casualizados, com quatro repetições e parcelas de $1,8 \mathrm{~m} \mathrm{x} 6,0 \mathrm{~m}$, obtendo-se uma área total de $10,8 \mathrm{~m}^{2}$.

Os herbicidas foram aplicados em uma única vez, em pós-emergência, em 03/12/93, quando as plantas de estrelinha apresentavam-se com 2 a 4 folhas, utilizando-se um pulverizador costal pressurizado a $\mathrm{CO}_{2}$, com barra de $2,0 \mathrm{~m}$., com quatro bicos do tipo leque 110.03 a $0,5 \mathrm{~m}$ do solo, com vazão de $200 \mathrm{l} / \mathrm{ha}$, usando-se uma pressão constante de $2,109 \mathrm{~kg} /$ $\mathrm{cm}^{2}$, no estágio de 1 a 2 trifólios da cultura de soja. As aplicações foram realizadas entre 9:30 e 10:30 horas, com velocidade do vento de $6 \mathrm{~km} / \mathrm{h}$. O céu apresentava-se claro e com temperatura do ar de $21^{\circ} \mathrm{C}$ e umidade relativa de $75 \%$. A ocorrência de precipitações pluviais está registrada na Tabela 2.

Tabela 2. Precipitações pluviais ocorridas durante a condução do ensaio de campo. São GotardoMG, 1993.

\begin{tabular}{|c|c|c|c|c|}
\hline \multirow[b]{2}{*}{ Mês } & \multicolumn{4}{|c|}{ Precipitações pluviais (mm) } \\
\hline & $\begin{array}{c}1^{0} \\
\text { Decêndio }\end{array}$ & $\begin{array}{c}2^{0} \\
\text { Decêndio } \\
\end{array}$ & $\begin{array}{c}3^{0} \\
\text { Decêndio }\end{array}$ & Total \\
\hline Novembro & 40 & 10 & 80 & 130 \\
\hline Dezembro & 44 & 124 & 138 & 306 \\
\hline Janeiro & 140 & 97 & 9 & 246 \\
\hline Fevereiro & 196 & 121 & 210 & 527 \\
\hline Março & 28 & 44 & 90 & 162 \\
\hline Abril & 36 & 102 & 0 & 138 \\
\hline Maio & 28 & 12 & 0 & 40 \\
\hline Total & & & & 1549 \\
\hline
\end{tabular}

Para o controle das pragas usou-se o inseticida Valon a $60 \mathrm{ml} / \mathrm{ha}$, aplicado 45 dias após plantio. Foram realizadas avaliações visuais de toxicidade à soja aos 16 e 60 dias após a aplicação dos herbicidas. Utilizou-se uma escala percentual de injúria variando de 0 a $100 \%$.

O nível de infestação no ensaio foi bastante significativo, visto que esta espécie daninha apresentou uma média bem alta de indivíduos por $\mathrm{m}^{2}$ aos 16 dias após a aplicação (366 indivíduos $/ \mathrm{m}^{2}$ ). Aos 16, 40, 60 e 132 dias após a aplicação dos herbicidas realizaram-se avaliações da eficácia de controle, utilizando-se a escala percentual de 0 a $100 \%$, onde $0 \%$ corresponde a nenhum controle e $100 \%$ ao controle total (excelente), para esta espécie de planta daninha.

Aos 132 dias após a aplicação foi realizada uma avaliação visual para a colheita mecânica, segundo a escala visual de 1 a 5, em que 5=impossível ( 80 a 100\% de infestação); 4=alta infestação (60 a 80\%); 3=infestação razoável (40 a $60 \%$ de infestação); $2=$ boa colheita ( 20 a $40 \%$ de infestação) e $1=$ excelente ( 0 a $20 \%$ de infestação).

\section{RESULTADOS E DISCUSSÃO}

As condições climáticas locais onde foi conduzido o ensaio de campo foram ótimas para a ocorrência e desenvolvimento da planta daninha, como para a cultura da soja. 
Tabela 3. Resultados médios obtidos na avaliação da eficácia biológica do herbicida chlorimuron-ethyl, isolado e em mistura, na cultura da soja. São Gotardo-MG, 1993/94.

\begin{tabular}{|c|c|c|c|c|}
\hline \multirow{3}{*}{ Tratamento } & \multirow{3}{*}{$\begin{array}{l}\text { Dose } \\
\text { (g/ha) }\end{array}$} & \multirow{3}{*}{$\begin{array}{l}\text { Avaliação } \\
\text { Colheita } \\
\text { Mecânica } \\
\text { (1 a 5) }\end{array}$} & \multirow{2}{*}{\multicolumn{2}{|c|}{$\begin{array}{c}\text { Fitointoxicação (\%) } \\
\text { Dias Após os } \\
\text { Tratamentos }\end{array}$}} \\
\hline & & & & \\
\hline & & & 16 & 60 \\
\hline Chlorimuron-ethyl + óleo mineral & $12,5+0,05 \%$ & $1,25 b^{(1)}$ & $1,0 \mathrm{~b}$ & 0,0 \\
\hline Chlorimuron-ethyl + óleo mineral & $15,0+0,05 \%$ & $1,50 \mathrm{~b}$ & $2,0 \mathrm{~b}$ & 0,0 \\
\hline Chlorimuron-ethyl + lactofen & $12,5+120$ & $1,25 \mathrm{~b}$ & 8,0 a & 0,0 \\
\hline Chlorimuron-ethyl + fomesafen + óleo mineral & $12,5+150+0,05 \%$ & $1,25 \mathrm{~b}$ & $2,0 \mathrm{~b}$ & 1,2 \\
\hline Chlorimuron-ethyl + imazethapyr & $12,5+30$ & $1,00 \mathrm{~b}$ & $1,0 \mathrm{~b}$ & 2,5 \\
\hline Testemunha sem capina & - & $5,00 \mathrm{a}$ & $0,0 \mathrm{~b}$ & 0,0 \\
\hline Média Geral & & 1,90 & 2,3 & 0,6 \\
\hline Valor de F & & $63,38 * *$ & $17,49 * *$ & - \\
\hline DMS & & 1,1 & 3,6 & - \\
\hline CV (\%) & & 16,4 & 62,6 & \\
\hline
\end{tabular}

${ }^{1}$ As médias, assinaladas pela mesma letra, não diferem significativamente, pelo teste de Tukey $5 \%$ DE probabilidade

Tabela 4. Resultados médios obtidos na avaliação da eficácia biológica do herbicida chlorimuron-ethyl, isolados e em mistura, no controle da estrelinha (Melampodium perfoliatum), na cultura da soja. São Gotardo MG,1993/94.

\begin{tabular}{|c|c|c|c|c|c|}
\hline \multirow{3}{*}{ Tratamento } & \multirow{3}{*}{$\begin{array}{l}\text { Dose } \\
\text { (g/ha) }\end{array}$} & \multicolumn{4}{|c|}{ Melampodium perfoliatum $^{1}$} \\
\hline & & \multicolumn{4}{|c|}{ Dias Após os Tratamentos } \\
\hline & & 16 & 40 & 60 & 132 \\
\hline Chlorimuron-ethyl + óleo mineral & $12,5+0,05 \%$ & $92,5 \mathrm{a}^{2}$ & $98,2 \mathrm{a}$ & $97,5 \mathrm{a}$ & $95,2 \mathrm{a}$ \\
\hline Chlorimuron-ethyl + óleo mineral & $15,0+0,05 \%$ & $97,0 \mathrm{a}$ & $99,5 \mathrm{a}$ & $99,5 \mathrm{a}$ & $97,0 \mathrm{a}$ \\
\hline Chlorimuron-ethyl + lactofen & $12,5+120$ & 96,2 a & $99,2 \mathrm{a}$ & $96,5 \mathrm{a}$ & $96,5 \mathrm{a}$ \\
\hline Chlorimuron-ethyl + fomesafen + óleo mineral & $12,5+150+0,05 \%$ & 97,0 a & 98,7 a & $98,0 \mathrm{a}$ & 99,5 a \\
\hline Chlorimuron-ethyl + imazethapyr & $12,5+30$ & $100,00 \mathrm{a}$ & $99,2 \mathrm{a}$ & $98,5 \mathrm{a}$ & 99,2 a \\
\hline Testemunha sem capina & - & $0,0 \mathrm{~b}$ & $0,0 \mathrm{~b}$ & $0,0 \mathrm{~b}$ & $0,0 \mathrm{~b}$ \\
\hline $\mathrm{N}^{\circ}$ de indivíduos & & 366,0 & $273,7^{* *}$ & $170,2 * *$ & \\
\hline Valor de F & & $81,1 * *$ & 5,6 & 7,8 & $68,4 * *$ \\
\hline CV $(\%)$ & & 10,0 & 5,6 & 7,8 & 16,3 \\
\hline
\end{tabular}

${ }^{1}$ Dados transformados em Arco Seno $\sqrt{x / 100}$ para efeito de análise da variância.

${ }^{2}$ As médias, assinaladas pela mesma letra, não diferem significativamente, pelo teste de Tukey a $5 \%$ de probabilidade.

No que concerne à toxicidade às plantas de soja, verificou-se que nenhum dos herbicidas isolados e em mistura nas doses testadas, apresentou efeitos negativo. O máximo valor alcançado foi quando aplicou-se chlorimuron-ethyl + lactofen, com 8\% de injúria aos 16 dias após a aplicação, sendo que aos 60 dias essa injúria era de $0 \%$ (Tabela 3 ).

Na avaliação visual para colheita mecânica, pode-se verificar que todos os herbicidas nas doses testadas apresentaram valores entre 1,0 e 1,5 (excelente), aos 132 dias após a aplicação (Tabela 3).

A atividade do chlorimuron-ethyl (12,5 e $15 \mathrm{~g} / \mathrm{ha})+$ óleo mineral $(0,05 \% \mathrm{v} / \mathrm{v})$ até 132 dias após a aplicação, apresentou índices de 95 e 97\%, respectivamente, observando-se um eficiente controle da estrelinha (Tabela 4). Quando o chlorimuron-ethyl foi misturado com lactofen, fomesafen e imazethapyr, ocorreu um excelente controle até os 132 dias após a aplicação, com índices de 96 a 99\% de controle.

\section{CONCLUSÕES}

1. Chlorimuron-ethyl (12,5 e $15 \mathrm{~g} / \mathrm{ha})+$ óleo mineral $(0,05 \%$ $\mathrm{v} / \mathrm{v}$ ), demonstrou uma eficácia muito boa (acima de 90\%) no controle da estrelinha (Melampodium perfoliatum) e reúne condições para ser utilizado, na cultura da soja, em pósemergência inicial da espécie mencionada. 
2. Chlorimuron-ethyl + lactofen $(12,5+120 \mathrm{~g} / \mathrm{ha})$, chlorimuronethyl + fomesafen + óleo mineral $(12,5+150 \mathrm{~g} / \mathrm{ha})$ e chlorimuronethyl + imazethapyr $(12,5+30 \mathrm{~g} / \mathrm{ha})$, em mistura de tanque, demostraram eficácia no controle da estrelinha e reúnem condições para serem utilizadas, na cultura da soja, em pós-emergência inicial da espécie mencionada.

3. Chlorimuron-ethyl isolado e em misturas de tanque com lactofen, fomesafen ou imazethapyr, nas doses testadas, demostraram seletividade para a cultura de soja, quando apli- cados em pós-emergência inicial.

\section{LITERATURA CITADA}

KISSMANN, K. Melampodium perfoliatum (Cav.) H.B.K., 4p, 1994 (mimeografado). 